\title{
The effects of pneumoperitoneum pressure on blood gases, respiratory and venous systems during laparoscopic cholecystectomy: A prospective randomized trial
}

\author{
Nihat Aksakal, ${ }^{1}$ Korhan Taviloğlu, ${ }^{1}$ Hakan Teoman Yanar, ${ }^{1}$ Simru Tuğrul, ${ }^{2}$ \\ Adem Uçar, ${ }^{3}$ Mustafa Tükenmez, ${ }^{1}$ Ali Fuat Kaan Gök, ${ }^{1}$ Fatih Yanar ${ }^{1}$ \\ 'Department of General Surgery, Istanbul University Istanbul Faculty of Medicine, Istanbul, Turkey \\ 2Department of Anesthesiology and Intensive Care, Istanbul University Istanbul Faculty of Medicine, Istanbul, Turkey \\ ${ }^{3}$ Department of Radiology, Istanbul University Istanbul Faculty of Medicine, Istanbul, Turkey
}

\begin{abstract}
Introduction: Increased abdominal pressure during pneumoperitoneum may distress respiratory functions and venous systems. The aim of this study was to evaluate the effect of low and high pneumoperitoneum pressure during laparoscopic cholecystectomy.

Materials and Methods: Total of 40 patients were randomized for use of either low $(8 \mathrm{mmHg})$ or high (14 $\mathrm{mmHg}$ ) pneumoperitoneum pressure. Respiratory mechanics were monitored continuously, arterial blood gases were analyzed via radial artery catheter, and duplex scan of left common femoral vein was performed. Ten days after surgery, venous duplex scan of lower limbs was used to detect signs of deep vein thrombosis.

Results: While peak inspiratory pressure significantly increased with low and high pneumoperitoneum pressure, dynamic compliance significantly decreased. Although carbon dioxide insufflation caused decrease in blood pH in both groups, it was only significant at high pneumoperitoneum pressure. Duplex scan of femoral vein revealed significant increase in diameter and decrease in peak blood velocity at high pneumoperitoneum pressure.
\end{abstract}

Conclusion: Respiratory acidosis may occur due to decreased compliance, and pneumoperitoneum causes reversible venous stasis, especially during use of high pressure. Results indicated that performing laparoscopy with lower pneumoperitoneum pressure decreased these adverse effects, especially in patients with cardiopulmonary comorbid diseases. Prophylaxis for venous thromboembolism in high-risk patients undergoing laparoscopic cholecystectomy is recommended.

Keywords: Acid-base balance; deep vein thrombosis; laparoscopy; pneumoperitoneum; pulmonary mechanics; venous stasis. 


\section{Introduction}

Laparoscopy with carbon dioxide $\left(\mathrm{CO}_{2}\right)$ pneumoperitoneum significantly infl uences blood gases, respiratory and deep venous systems. Although there are many experimental studies performed on animal models, the infl uence of different pneumoperitoneum pressures on patients' blood gases, respiratory, and venous systems is not clear and some effects of pneumoperitoneum on human body still remains controversial. ${ }^{[1-10]}$ Intraoperative venous stasis may increase the risk for preoperative or postoperative deep vein thrombosis and pulmonary embolism, especially during laparoscopic procedures. ${ }^{[8,11-15]}$ Some authors favor venous thromboembolism (VTE) prophylaxis, whereas some not. ${ }^{[12,13,16]}$ This paper reports the result of a prospective study investigating the effect of different pneumoperitoneum pressures $(8 \mathrm{mmHg}$ or 14 $\mathrm{mmHg}$ ) on arterial blood gas, respiratory parameters, and venous system during laparoscopic cholecystectomy (LC).

\section{Materials and Methods}

All patients evaluated for the laparoscopic treatment of acute cholecystitis were considered to take part in the trial. Patients over 60 years of age with pulmonary or cardiac disease, previous surgeries, a history of venous or arterial diseases were excluded. All patients were in class I and II according to the American Society of Anesthesiology (ASA) classification.

The local ethics committee approved the study protocol. Following written valid consents of the patients, they were randomly assigned to LC under $8 \mathrm{mmHg}$ (Group I) or $14 \mathrm{mmHg}$ (Group II) pneumoperitoneum pressures (PP). Randomization was performed using sealed envelopes. A total of 40 patients were randomized as 20 being in each group. Hospital stay, operation time, mortality and morbidities were recorded.

$\mathrm{CO}_{2}$ pneumoperitoneum was executed by a Veress needle initially at a slow fl ow $(1 \mathrm{~L} / \mathrm{min})$ and then faster fl ow (maximum $20 \mathrm{~L} / \mathrm{min}$ ) to avoid a vasovagal reaction. Before insufflation, during pneumoperitoneum and following desufflation, respiratory mechanics were recorded and dynamic compliance, peak inspiratory pressure, and arterial blood gases were analyzed by a blood gas analyzer from the radial artery catheter. Arterial blood samples were taken puncturing the left radial artery prior to pneumoperitoneum, 20 minutes after pneumoperitoneum and 20 minutes after desufflation. The following parameters of acid-base balance were recorded: $\mathrm{pH}, \mathrm{PaCO}_{2}, \mathrm{PaO}_{2}, \mathrm{HCO}_{3}$, base excess.
Peak blood velocity and diameter of left common femoral vein were measured by color duplex scanning before insufflation, during pneumoperitoneum and following desufflation. Ten days after surgery, lower limbs were examined by a venous duplex scanning to detect signs of deep vein thrombosis.

Anesthesia was induced with intravenous (IV) propofol (2 $\mathrm{mg} / \mathrm{kg})$ and fentanyl $(1 \mu \mathrm{g} / \mathrm{kg})$, followed by vecuronium $(0.1 \mathrm{mg} / \mathrm{kg})$ for intubation and carried with sevofl urane (1 MAC minimum alveolar concentration).

A ventilator was used for artificial lung ventilation at a rate of 12 breaths $/ \mathrm{min}$ and tidal volume of $10 \mathrm{~mL} / \mathrm{kg}$, with a mixture of air and oxygen $\left(\mathrm{FiO}_{2} 40 \%\right)$. All patients received prophylactic antibiotic as cefazolin sodium $1 \mathrm{~g}$. The fourtrocar technique was preferred and all patients were operated on in $15^{\circ}$ reverse Trendelenburg position with slightly $\left(10^{\circ}\right)$ rotated to the left side.

Instat Statistical Package (GraphPad, CA, USA) was used for statistical analysis. Suitable data were expressed as mean \pm standard deviations. Student's t-test and ANOVA were used for statistical analysis. Statistical significance level was established as $\mathrm{p}<0.05$.

\section{Results}

The groups were well matched and there were no significant differences of age, sex, body mass index (BMI), operating time, anesthesia time, ASA class, and mortality and morbidity rate between the groups (Table 1). Although mean operating time and anesthesia time were longer in Group I (8 mmHg-PP) than in Group II (14 mmHg-PP), they were not statistically significant.

There were no serious complications in both groups. Wound infection was observed in one patient in Group I and one in Group II had fever secondary to atelectasis.

There was no mortality in both groups. The effects of PP with low and high pressures on arterial blood gases, acidbase balance (ABB), respiratory and deep venous systems are compared at Table 2 .

\section{Arterial Blood Gases and ABB}

Blood pH decreased slightly by 8 and $14 \mathrm{mmHg}$ after intraperitoneal insufflation which was also noticed after desufflation. Only in Group II, the decrease between PP and before insufflation was statistically significant $(\mathrm{p}<0.001)$. However, a gradual decrease toward normal values $(\mathrm{pH}$ 


\begin{tabular}{lccc}
\hline \multicolumn{4}{l}{ Table 1. Patients' characteristics and operative data } \\
& Group 1 & Group 2 & p \\
\hline Mean age (years) & $46.3( \pm 8.2)$ & $46.5( \pm 8.2)$ & $>0.05$ \\
Sex (male/female) & $6 / 14$ & $5 / 15$ & $>0.05$ \\
BMI & $28.7(22.4-36.3)$ & $27.1(23.2-35.4)$ & $>0.05$ \\
ASA class (I/2) & $13 / 7$ & $14 / 6$ & $>0.05$ \\
Operating time (minutes) & $62.8 \pm 25.6$ & $55.7 \pm 18.4$ & $>0.05$ \\
Anesthesia time (minutes) & $72.8 \pm 23.2$ & $56.9 \pm 16.9$ & $>0.05$ \\
Morbidity rate (\%) & 5 & 5 & $>0.05$ \\
\hline Values are mean \pm standard deviation. & & & \\
\hline
\end{tabular}

7.35-7.45) was noticed. The $\mathrm{PaCO}_{2}$ levels considerably increased with pneumoperitoneum. While this wasn't significant during PP in both groups, it was significant after desufflation. In the measurement of arterial $\mathrm{PaCO}_{2}$ fit $\mathrm{pH}$ values, no significant differences were found between the groups by a mean of $\mathrm{PaO}_{2}$ at the same steps of operation. No statistically significant differences were found between the groups and comparisons in the groups by mean of $\mathrm{PaO}_{2}$.

In Group I, there was no significant difference among preinsufflation, during insufflation and after desufflation by mean of $\mathrm{HCO}_{3}(\mathrm{p}>0.05)$. However, in Group II, bicarbonate level decreased moderately during insufflation and continued till after insufflation. In this group, there was a significant difference between pre-insufflation and during insufflation ( $p<0.001)$, during insufflation and after desufflation ( $p<0.05)$. There was no significant decrease during insufflation in two groups by mean of $\mathrm{HCO}_{3}$; however, it was noticed after desufflation in Group II rather than in Group I. All BE values were found in normal range. Statistical difference was recorded in Group II during insufflation and after desufflation. Although BE was lower in Group II than in Group I, no significant differences were found between the two groups by mean of $\mathrm{BE}$.

\section{Respiratory Parameters}

Peak inspiratory pressure (PIP) was followed during the study. In Group I, PIP increased significantly during insufflation rather than before insufflation. After desufflation, PIP was close to the PIP values before insufflation. In addition, during insufflation, PIP increased to higher values compared to pre-insufflation which was significant in Group II $(\mathrm{p}<0.01)$. These changes were reversible after desufflation. No significant difference was found in two

Table 2. The effects of different insufflation pressures on arterial blood gases, acid-base balance (ABB), respiratory and deep venous systems

\begin{tabular}{|c|c|c|c|c|c|c|}
\hline & \multicolumn{2}{|c|}{ Before insufflation } & \multicolumn{2}{|c|}{ During pneumoperitoneum } & \multicolumn{2}{|c|}{ After desufflation } \\
\hline & Group 1 & Group 2 & Group 1 & Group 2 & Group 1 & Group 2 \\
\hline $\mathrm{DC}\left(\mathrm{mL} / \mathrm{cmH}_{2} \mathrm{O}\right)$ & $30 \pm 4.9$ & $32.1 \pm 6.3^{\star *}$ & $26.6 \pm 5.4^{* *}$ & $26.2 \pm 5.6^{* *}$ & $31.2 \pm 5.3^{\star *}$ & $32.6 \pm 6.7^{\star *}$ \\
\hline $\mathrm{PIP}(\mathrm{mmHg})$ & $24.2 \pm 4.4$ & $24.2 \pm 3.67^{* *}$ & $27.1 \pm 5.17^{* *}$ & $28.6 \pm 4.3^{* *}$ & $23.6 \pm 4.3^{* *}$ & $24.6 \pm 5^{* \star}$ \\
\hline $\mathrm{pH}$ & $7.41 \pm 0.04$ & $7.44 \pm 0.04$ & $7.39 \pm 0.03$ & $7.40 \pm 0.05$ & $7.37 \pm 0.05$ & $7.37 \pm 0.05$ \\
\hline $\mathrm{PaCO}_{2}$ & $33.35 \pm 3.31$ & $31.54 \pm 3.47$ & $34.99 \pm 3.86$ & $34.99 \pm 3.86$ & $38.12 \pm 7.52$ & $36.59 \pm 6.27$ \\
\hline $\mathrm{PaO}_{2}$ & $252.60 \pm 33.52$ & $266.80 \pm 67.30$ & $247.90 \pm 48.79$ & $239.0 \pm 77.2$ & $250.10 \pm 56$ & $219.52 \pm 74.27$ \\
\hline $\mathrm{HCO}_{3}$ & $24.47 \pm 2.97$ & $24.10 \pm 0.96$ & $24.58 \pm 5.04$ & $23.52 \pm 1.57$ & $24.42 \pm 6.79$ & $22.35 \pm 2.14$ \\
\hline $\mathrm{BE}$ & $0.12 \pm 1.46$ & $-0.73 \pm 1.48$ & $0.09 \pm 1.73$ & $-1.18 \pm 1.72$ & $-0.86 \pm 1.95$ & $-1.54 \pm 2.10$ \\
\hline FV flow speed (cm/sc) & $17.2 \pm 8.1$ & $24.6 \pm 3.8^{*, * *}$ & $16.6 \pm 8.2$ & $20.3 \pm 3.6^{*, * \star}$ & $14.5 \pm 8.4$ & $23.7 \pm 5^{\star}$ \\
\hline FV diameter (mm) & $11.04 \pm 3.1$ & $12.5 \pm 1.31^{*}$ & $11.14 \pm 3.21$ & $12.52 \pm 1.90^{*, * *}$ & $9.9 \pm 2.69$ & $10.59 \pm 1.25^{* *}$ \\
\hline
\end{tabular}


groups by mean of PIP, recorded at the same steps of the surgery. Dynamic compliance (TV/PlatoP-PEEP) was decreased during insufflation, compared to before insufflation in both groups. During insufflation $(\mathrm{p}<0.05)$ and after desufflation dynamic compliance decreased to normal values at the beginning in Group I. Same changes were detected in Group II. The significant decrease in DC was determined during insufflation, rather than before insufflation ( $\mathrm{p}<0.05$ ). In this group, after desufflation, dynamic compliance decreased to values prior to insufflation. DC changes at the same steps of the operation were found insignificant.

\section{Venous System}

Left femoral vein diameter was consistent with peak blood velocity. In Group I, an increase on left femoral vein diameter and a decrease in peak blood velocity per second during insufflation were observed; however, these changes were not statistically significant. In group II, although an increase in left femoral vein diameter was statistically insignificant, a significant decrease in peak velocity per second was revealed $(\mathrm{p}<0.001)$. In both groups, after desufflation, femoral vein diameter returned to the values prior to insufflation. An increase in the left femoral vein diameter and a decrease in peak blood velocity per second during insufflation in Group II was significantly different from Group I; however, no statistically significant changes were determined following desufflation in both groups by mean of diameter and peak blood velocity. Ten days after surgery, lower limb venous duplex scanning and one deep vein thrombosis were detected in each group. LMWH was used for the treatment of these two patients.

\section{Discussion}

Currently, laparoscopic surgery has gained widespread acceptance for the diagnosis and treatment of many diseases. Insufflation is, one of the basic features of laparoscopic surgery, provides the space needed for best view and optimal working. Since laparoscopic surgery needs smaller incisions and less dissections when compared to open surgery, patients have less postoperative pain and less complications including wound infection, respiratory and gastrointestinal complications. Additionally, it is preferred by surgeons and patients as it provides better cosmetic outcomes reducing hospitalization time and shortening the time needed to return to daily activities.

However, $\mathrm{PP}$ with $\mathrm{CO}_{2}$ insufflation, the basic process of laparoscopic surgery, is accompanied by a certain number of pathophysiological changes which are suggested to be in relation with increases in intraabdominal pressure (IAP) and $\mathrm{CO}_{2}$ absorption through peritoneum and its transition into the systemic circulation. Although there are many experimental and clinical studies regarding these effects of PP, its infl uences on arterial blood gases, respiratory and deep venous systems are unclear and its effects on human body are still controversial. ${ }^{[1,10]}$

Increased IAP is associated with diaphragm elevation causing an increase in the intrathoracic pressure while resulting in an increase in the diaphragm tension and restraining lung expansion. Therefore, compression atelectasia occurs. As the number of ventilated alveoli decrease, dead space expands and causes the lung functional residual capacity to decrease. As a result, ventilation-perfusion mismatch appears. As IAP increases, dynamic compliance reduces whereas airway pressure, PP, and plateau pressures increase. ${ }^{[17-22]}$ In our study, significant decreases in DC and increases in PIP during PP in both high and low PP groups were detected. In reference to the high PP group, decrease in DC and increase in PIP were less significant in low PP group. Following desufflation, DC and PIP values returned to initial values before insufflation. Proportionately, with the increase in IAP, significant changes in DC and PIP were detected.

$\mathrm{CO}_{2}$, the ideal gas to compose $\mathrm{PP}$, reaches the maximum levels in circulation within a short time after being absorbed rapidly through peritoneum. Some researchers suggest that $\mathrm{CO}_{2}$ absorption time increases proportionately with the operation time and IAP increase; however, others report that there is no proportional relationship between IAP and peritoneal absorption of $\mathrm{CO}_{2}{ }^{[18,23]} \mathrm{CO}_{2}$ elimination occurs directly from lungs by ventilation. Elimination is directly proportional with cardiac output and ventilation rate. Supporters of the idea that increases in IAP and $\mathrm{CO}_{2}$ absorption are directly proportional suggest that $\mathrm{CO}_{2}$ elimination through lungs is limited as a result of increased intrathoracic pressure, decreased cardiac output, limitation of the expansion capacity of lungs, occurrence of compression atelectasia, and ventilation- perfusion mismatch due to diaphragm elevation.

The researchers supporting the idea that trans-peritoneal absorption of $\mathrm{CO}_{2}$ reduces as the IAP increases suggest that IAP limits absorption of $\mathrm{CO}_{2}$ through capillary vessels with compression impact on peritoneal capillary vessels. In our study, despite not being statistically significant, 
$\mathrm{PaCO}_{2}$ increased during $\mathrm{PP}$ and more during high pressure insufflations. Following desufflation, $\mathrm{PaCO}_{2}$ increased in both groups, more in high insufflation pressures, as well. Although mean operation and anesthesia time were shorter, $\mathrm{PaCO}_{2}$ values increased more significantly during high insufflation pressures in comparison with low pressures indicating the linear association between IAP and $\mathrm{PaCO}_{2}$.

Elimination of $\mathrm{CO}_{2}$ from circulation occurs directly by ventilation through lungs. Insufficient ventilation leads to $\mathrm{CO}_{2}$ aggregation, especially in bones and muscles. Significant increase in $\mathrm{PaCO}_{2}$ following desufflation may be a result of $\mathrm{CO}_{2}$ release from tissues into circulation. Insufficient ventilation may cause hypercapnia and acidosis. ${ }^{[24]}$ Persistent hypercapnia induces renal response including $\mathrm{H}+$ secretion from renal tubuli and bicarbonate passage into the extracellular zone. As almost all $\mathrm{CO}_{2}$ is eliminated during laparoscopy, compensatory hyperventilation is required in order to prevent hypercapnia and acidosis.

Intra-abdominal pressure changes during insufflation have infl uences on ABB. This may cause major problems during and after surgery especially in patients with respiratory and cardiac co-morbidities. High IAP may result in acid-base imbalance increasing $\mathrm{CO}_{2}$ absorption through peritoneum and limiting $\mathrm{CO}_{2}$ elimination by ventilation particularly with an increase in operation time. Some experimental and clinical studies suggest that abdominal pressure formed by $\mathrm{CO}_{2}$ changes $\mathrm{ABB}$ towards acidosis and hypercapnia. ${ }^{[25-28]}$ Although the mechanisms causing these changes are still unclear, predominant opinions suggest acidosis associated with trans-peritoneal $\mathrm{CO}_{2} \mathrm{ab}$ sorption rather than negative effects of increased IAP on ventilation. ${ }^{[29,30]}$

Sefr and colleagues indicate that there is no statistically significant difference in $\mathrm{ABB}$ between $10 \mathrm{mmHg}$ and 15 mmHg pressures in a clinical study on ASA I and ASA II patients. ${ }^{[31]}$ In our study, a slight decrease in blood $\mathrm{pH}$ was detected following both low and high pressure preumoperitoneum, which was also observed after desufflation.

Statistically significant decrease was detected only in high pressure pneumoperitoneum group. Despite this decrease, $\mathrm{pH}$ ranged between normal values (7.35-7.45). In high pressure group, statistically significant $(p<0.001)$ decrease in $\mathrm{HCO}_{3}$ parallel to changes in $\mathrm{pH}$ was identified, which continued significantly after desufflation ( $p>0.05$ ). In low pressure group, statistically insignificant decrease in $\mathrm{HCO}_{3}$ during pneumoperitoneum and after desufflation was detected. Although all BE measurements ranged between normal values, BE values during insufflation and after desufflation showed significant changes only in high pressure group. These results indicate negative effects of increased IAP on respiratory system besides arterial blood gases and ABB. Although these pathophysiological changes do not cause abnormalities in patients with normal respiratory functions, they may result in hypoxia in patients with COPD or emphysema.

However, in laparoscopic interventions with high IAP some cardio-vascular changes also occur and cause serious problems in patients with low cardiac reserve. These changes are infrequent in interventions with low IAP. We suggest that high risk patients with cardiac and respiratory diseases can be operated with lower morbidity and mortality rates by obtaining well cardio-pulmonary monitorization and avoiding unnecessary patient positions.

Increased IAP leads to decrease in venous return in lower extremity veins as a result of direct compression on IVC and iliac veins. In surgical procedures practiced on anti-Trendelenburg position, as a result of gravity, compression of visceral organs on iliac veins cause deceleration in femoral blood fl ow. Deceleration effects of increased ICP and anti-Trendelenburg position on femoral vein $\mathrm{fl}$ ow has already been shown. ${ }^{[32]}$ It was suggested that these effects on deep venous system induce the factors composing the Virchow triad. However, some authorities do not recommend routine VTE prophylaxis.

In our study, the effects of low and high pressure PP on femoral vein blood fl ow velocity and diameter were compared and a statistically insignificant increase in the left common femoral vein diameter and decrease in peak blood fl ow velocity per second during PP were detected. With high pressure PP, statistically insignificant increase in CFV diameter and a significant $(\mathrm{p}<0.001)$ decrease in peak blood fl ow velocity per second during PP were determined. These results indicate that increased IAP causes deceleration in the blood fl ow of the deep venous system and stasis, the major etiological factor for DVT. Deep venous system Doppler examination of the lower extremities on the postoperative tenth day showed asymptomatic DVT in one patient in each group despite early mobilization.

Although laparoscopic surgery has currently gained widespread acceptance, debates on routine VTE prophylaxis still continue. Since the real incidence of DVT and PE af- 
ter laparoscopic surgery is unknown and the number of our subjects was insufficient, it is not possible to identify the need for routine VTE prophylaxis in laparoscopic surgery accurately. However, in the light of the results of the study, routine VTE prophylaxis in patients who are at high risk for laparoscopic surgery is recommended.

\section{Conclusion}

Increase in intra-abdominal pressure during pneumoperitoneum affects respiratory functions, decreases dynamic compliance, and increases PIP. It changes arterial blood gases and acid-base balance towards hypercapnia and acidosis. It causes stasis in the deep venous system and correspondingly increases the risk for VTE. Patients at high risk for cardiac and respiratory diseases can be operated with low pneumoperitoneum pressures with lower morbidity and mortality. Prophylaxis for venous thromboembolism in patients carrying risk for laparoscopic cholecystectomy is recommended.

\section{Disclosures}

Ethichs Committee Approval: The study was approved by the Local Ethics Committee.

Peer-review: Externally peer-reviewed.

Conflict of Interest: None declared.

\section{References}

1. McMahon AJ, Russell IT, Baxter JN, Ross S, Anderson JR, Morran CG, et al. Laparoscopic versus minilaparotomy cholecystectomy: a randomised trial. Lancet 1994;343:135-8.

2. Noirot D, Joris J, Legrand M, Lamy M. Hemodynamic changes during pneumoperitoneum for laparoscopic cholecystectomy. Anesthesiology 1992;77:A69. [CrossRef]

3. Koivusalo AM, Kellokumpu I, Scheinin M, Tikkanen I, Halme $\mathrm{L}$, Lindgren L. Randomized comparison of the neuroendocrine response to laparoscopic cholecystectomy using either conventional or abdominal wall lift techniques. $\mathrm{Br} \mathrm{J}$ Surg 1996;83:1532-6. [CrossRef]

4. Chang DT, Kirsch AJ, Sawczuk IS. Oliguria during laparoscopic surgery. J Endourol 1994;8:349-52. [CrossRef]

5. McGrath BJ, Zimmerman JE, Williams JF, Parmet J. Carbon dioxide embolism treated with hyperbaric oxygen. Can J Anaesth 1989;36:586-9. [CrossRef]

6. Hirvonen EA, Poikolainen EO, Pääkkönen ME, Nuutinen LS. The adverse hemodynamic effects of anesthesia, head-up tilt, and carbon dioxide pneumoperitoneum during laparoscopic cholecystectomy. Surg Endosc 2000;14:272-7.

7. Odeberg S, Ljungqvist $O$, Svenberg T, Gannedahl P, Bäckdahl M, von Rosen A, et al. Haemodynamic effects of pneu- moperitoneum and the influence of posture during anaesthesia for laparoscopic surgery. Acta Anaesthesiol Scand 1994;38:276-83. [CrossRef]

8. Beebe DS, McNevin MP, Crain JM, Letourneau JG, Belani KG, Abrams JA, et al. Evidence of venous stasis after abdominal insufflation for laparoscopic cholecystectomy. Surg Gynecol Obstet 1993;176:443-7.

9. Diakun TA. Carbon dioxide embolism: successful resuscitation with cardiopulmonary bypass. Anesthesiology 1991;74:1151-3. [CrossRef]

10. Derouin M, Couture P, Boudreault D, Girard D, Gravel D. Detection of gas embolism by transesophageal echocardiography during laparoscopic cholecystectomy. Anesth Analg 1996;82:119-24. [CrossRef]

11. Alatri A, Tronci $M$, Bucciarelli $P$, Moia M. Venous thromboembolism after laparoscopic surgery: two case reports and review of the literature. Ann Ital Med Int 1998;13:53-5.

12. Lindberg F, Bergqvist D, Rasmussen I. Incidence of thromboembolic complications after laparoscopic cholecystectomy: review of the literature. Surg Laparosc Endosc 1997;7:324-31.

13. Catheline JM, Turner R, Gaillard JL, Rizk N, Champault G. Thromboembolism in laparoscopic surgery: risk factors and preventive measures. Surg Laparosc Endosc Percutan Tech 1999;9:135-9. [CrossRef]

14. Ortega $A E$, Peters JH, Incarbone R, Estrada L, Ehsan A, Kwan $\mathrm{Y}$, et al. A prospective randomized comparison of the metabolic and stress hormonal responses of laparoscopic and open cholecystectomy. J Am Coll Surg 1996;183:249-56.

15. Millard JA, Hill BB, Cook PS, Fenoglio ME, Stahlgren LH. Intermittent sequential pneumatic compression in prevention of venous stasis associated with pneumoperitoneum during laparoscopic cholecystectomy. Arch Surg 1993;128:914-8.

16. Blake AM, Toker SI, Dunn E. Deep venous thrombosis prophylaxis is not indicated for laparoscopic cholecystectomy. JSLS 2001;5:215-9.

17. Wahba RW. Perioperative functional residual capacity. Can J Anaesth 1991;38:384-400. [CrossRef]

18. Hirvonen EA, Nuutinen LS, Kauko M. Ventilatory effects, blood gas changes, and oxygen consumption during laparoscopic hysterectomy. Anesth Analg 1995;80:961-6. [CrossRef]

19. Bardoczky GI, Engelman E, Levarlet M, Simon P. Ventilatory effects of pneumoperitoneum monitored with continuous spirometry. Anaesthesia 1993;48:309-11. [CrossRef]

20. Galizia G, Prizio G, Lieto E, Castellano P, Pelosio L, Imperatore $\mathrm{V}$, et al. Hemodynamic and pulmonary changes during open, carbon dioxide pneumoperitoneum and abdominal wall-lifting cholecystectomy. A prospective, randomized study. Surg Endosc 2001;15:477-83. [CrossRef]

21. Rauh R, Hemmerling TM, Rist M, Jacobi KE. Influence of pneumoperitoneum and patient positioning on respiratory system compliance. J Clin Anesth 2001;13:361-5. [CrossRef]

22. Dumont L, Mattys M, Mardirosoff C, Vervloesem N, Allé JL, Massaut $\mathrm{J}$. Changes in pulmonary mechanics during laparoscopic gastroplasty in morbidly obese patients. Acta Anaesthesiol Scand 1997;41:408-13. [CrossRef] 
23. Henny CP, Hofland J. Laparoscopic surgery: pitfalls due to anesthesia, positioning, and pneumoperitoneum. Surg Endosc 2005;19:1163-71. [CrossRef]

24. Lindgren L, Koivusalo AM, Kellokumpu I. Conventional pneumoperitoneum compared with abdominal wall lift for laparoscopic cholecystectomy. Br J Anaesth 1995;75:567-72.

25. Ho HS, Saunders CJ, Gunther RA, Wolfe BM. Effector of hemodynamics during laparoscopy: $\mathrm{CO} 2$ absorption or intra-abdominal pressure? J Surg Res 1995;59:497-503.

26. Gándara V, de Vega DS, Escriú N, Zorrilla IG. Acid-base balance alterations in laparoscopic cholecystectomy. Surg Endosc 1997;11:707-10. [CrossRef]

27. Volz J, Köster S, Spacek Z, Paweletz N. Characteristic alterations of the peritoneum after carbon dioxide pneumoperitoneum. Surg Endosc 1999;13:611-4. [CrossRef]

28. Kantorová I, Svoboda P, Ochmann J, Pestál M, Kozumplík L, Dolezalová $\mathrm{L}$, et al. Does insufflation of the abdomen in lap- aroscopic surgery affect acid-base and ventilatory parameters? Rozhl Chir 1999;78:332-6.

29. McMahon AJ, Baxter JN, Murray W, Imrie CW, Kenny G, O'Dwyer PJ. Helium pneumoperitoneum for laparoscopic cholecystectomy: ventilatory and blood gas changes. $\mathrm{Br} \mathrm{J}$ Surg 1994;81:1033-6. [CrossRef]

30. McMahon AJ, Russell IT, Ramsay G, Sunderland G, Baxter JN, Anderson JR, et al. Laparoscopic and minilaparotomy cholecystectomy: a randomized trial comparing postoperative pain and pulmonary function. Surgery 1994;115:533-9.

31. Sefr R, Puszkailer K, Jagos F. Randomized trial of different intraabdominal pressures and acid-base balance alterations during laparoscopic cholecystectomy. Surg Endosc 2003;17:947-50. [CrossRef]

32. Güleç B, Oner K, Yigitler C, Kocaoğlu M, Aydin Y, Sağlam M. Lower extremity venous changes in pneumoperitoneum during laparoscopic surgery. ANZ J Surg 2006;76:904-6. 